\title{
Causation in international relations
}

Book or Report Section

Accepted Version

Humphreys, A. R. C. (2020) Causation in international relations. In: James, P. (ed.) Oxford Bibliographies in International Relations. Oxford University Press. doi: https://doi.org/10.1093/OBO/9780199743292-0274 Available at https://centaur.reading.ac.uk/86586/

It is advisable to refer to the publisher's version if you intend to cite from the work. See Guidance on citing.

To link to this article DOI: http://dx.doi.org/10.1093/OBO/9780199743292-0274

Publisher: Oxford University Press

All outputs in CentAUR are protected by Intellectual Property Rights law, including copyright law. Copyright and IPR is retained by the creators or other copyright holders. Terms and conditions for use of this material are defined in the End User Agreement.

\section{www.reading.ac.uk/centaur}

\section{CentAUR}

Central Archive at the University of Reading

Reading's research outputs online 


\section{Causation in International Relations}

Adam R. C. Humphreys

Introduction

General Overview

Philosophical Background

Seminal Texts

Edited Collections

Causation in the Philosophy of Social Science

Causation in International Relations - Key Ideas

Causal Inference

Scientific and Critical Realism

Causal Explanation

History and Causal Inquiry

Causation in International Relations - Selected Examples

\section{Introduction}

Causal claims are bound into the fabric of International Relations (IR). Efforts to explain past outcomes, to predict future developments, to comprehend the range of options open to international actors, to advance policy prescriptions, and to evaluate policy decisions vis-à-vis possible alternatives all typically rely, explicitly or implicitly, on causal claims. Moreover, politicians, policymakers, and other state and non-state actors who seek to manipulate particular aspects of world politics are also (whether they realize it or not) typically acting on causal claims. Acquiring reliable causal knowledge is therefore extremely valuable. It is, however, a challenging task. The content of causal claims is shaped not only by relevant facts about the world, but also by ideas about causation itself, for example, about what 'causing' is, about the kinds of things that can be causes (and effects), about how causes can be identified, and about what constitutes an adequate causal explanation. These are tricky and controversial issues which are often submerged below the surface of our thinking. The challenge of arriving at a clear understanding is reflected in the divisions within work which explicitly engages with questions about causation in IR, divisions which are also found within the philosophical literature on which this work draws. It is also reflected in the tendency, within the broader discipline, to set questions about causation to one side, either because they are viewed as too hard to answer or because it is not obvious how answering them will improve our knowledge of world politics. In order to gain a full picture of debates about causation in IR and their implications for substantive topics it is helpful to explore three broad kinds of literature: first, the philosophical texts which provide the backdrop against which discussions of causation in IR take place; 
second, existing debates about causation in IR, encompassing both mainstream discussions of methods for causal inference and more specialist literatures on causal realism, the nature of causal explanation, and the relationship between historical and causal inquiry; and third, literature in IR which explicitly examines how positions on underlying questions about causation can and do shape positions on substantive topics in IR.

\section{General Overview}

In the mainstream discipline of IR, which Patrick Jackson characterizes as 'neopositivist' (Jackson 2011: 41-71), it is widely assumed not only that we can advance causal claims, but that we should, and that such claims are best generated through the application of particular methods of causal inquiry. Consequently, debates about causation occur principally at the level of methodology, for example, in discussions about the relative merits of quantitative and qualitative methods for causal inference. There is little explicit engagement with the underlying philosophical issues. Outside of this mainstream, two very different approaches to causation may be identified. On the one hand, many scholars of an interpretive or critical disposition disavow causal inquiry, regarding it as overly restrictive. On the other hand, the smaller group of scholars in IR who explicitly engage with philosophical debates about causation tend to be critical both of the mainstream discipline's prioritization of 'methods-talk' over engagement with the underlying issues and of the supposition that interpretive and critical approaches must be 'non-causal'. As a consequence of this diversity of approaches, gaining an overview of debates about causation in IR is difficult. A number of sources are, nonetheless, useful. Hollis and Smith 1991 is a classic introduction, though its narrow understanding of what causal inquiry consists in and its insistence that the kinds of questions that can be answered through causal inquiry are categorically different from those which can be answered through interpretive inquiry has been much criticized, for example in Kurki 2008. Suganami 1996, Kurki 2008, and Lebow 2014 are all stimulating book-length engagements with the topic of causation in IR, though each adopts a very different approach to the others. Grynaviski 2013 uses a substantive problem (how to explain the Cuban Missile Crisis) to highlight the importance of how we think about causation. Jackson 2011 provides a valuable survey of the background issues in the philosophy of science and social science. Humphreys 2017 introduces a collection of issues which showcases contemporary thinking about causation and causal explanation in IR.

Grynaviski, Eric. 'Contrasts, Counterfactuals, and Causes'. European Journal of International Relations 19, no. 4 (2013): 823-46.

Uses debates about the causes of the Cuban Missile Crisis as a foil for exploring how and why scholars of international relations disagree about what counts as a cause. Argues that many such disagreements can be overcome by focusing on the form taken by practical research questions and the kind of explanatory information they demand. 
Hollis, Martin, and Steve Smith. Explaining and Understanding International Relations. Oxford: Clarendon Press, 1991.

A classic, widely read introduction to different ways of thinking about world politics. Situates causal inquiry as part of 'explanation' and thereby distinguishes it categorically from interpretive 'understanding'. The narrow construal of causation and causal explanation to which this gives rise has since been widely criticised within IR.

Humphreys, Adam RC. 'Introduction: Problems of Causation in World Politics'. Journal of International Relations and Development 20, no. 4 (2017): 659-666.

Introduces a special edition of the Journal of International Relations and Development which showcases contemporary thinking about causation and causal explanation in IR and illustrates how philosophical considerations inform debates about a range of substantive topics in world politics.

Jackson, Patrick Thaddeus. The Conduct of Inquiry in International Relations: Philosophy of Science and its Implications for the Study of World Politics. Abingdon: Routledge, 2011.

Not exclusively focused on causation, but provides a valuable survey of the approaches to scientific knowledge production that are employed in IR and defended by philosophers and in relation to which positions on causation are situated. Defends a pluralist view in which there are multiple possible routes to scientific (and hence causal) knowledge.

Kurki, Milja. Causation in International Relations: Reclaiming Causal Analysis. Cambridge Studies in International Relations vol. 108. Cambridge: Cambridge University Press, 2008.

Links the divisions within IR around the nature and utility of causal analysis to the influence of David Hume's ideas on causal thinking in the social sciences. Proposes, in their place, a 'deeper and broader' understanding of causation which (compared to the Humean approach, and the position defended in Hollis and Smith 1991) expands the range of problems that causal analysis can address.

Lebow, Richard Ned. Constructing Cause in International Relations. Cambridge: Cambridge University Press, 2014.

Defends an idealist and constructivist account of causation as a category of understanding imposed on the world. Argues that, in IR, and in the social sciences more broadly, it is more productive to focus on developing causal narratives concerning the occurrence of specific outcomes of interest than to seek to develop causal generalizations.

Suganami, Hidemi. On the Causes of War. Oxford, Oxford University Press, 1996. Uses Kenneth Waltz's classic Man, The State and War(1959) as a foil for identifying the different kinds of questions we can ask about the causes of war and the different kinds of evidence that might 
help us to answer those questions. Makes a case for the analytical centrality of causal narratives which explain the origins of particular wars.

\section{Philosophical Background}

Many debates about causation in IR are informed by underlying philosophical ideas. For example, mainstream discussions of causal inference in IR draw on a counterfactual understanding of causation which was first explicitly defended by Lewis 1973 but which finds its roots in Hume (see, for example, Hume 1975: 76). By contrast, scientific and critical realists in IR argue against a 'Humean' understanding of causation (see Kurki 2008) and draw instead on the work of Bhaskar 2008 and other causal realists. In order to understand debates about causation in IR, it is therefore helpful to get a sense of this philosophical background. The issues that are most relevant to IR are three-fold: first, what causation is (including whether or not it is real); second, what constitutes a cause and how causes can be identified; and third, how explanation is linked to causation.

\section{Seminal Texts}

Philosophical debates about causation often refer back to certain seminal authors and texts. Of these, by far the most influential is Hume 1975[1777], who asked where our idea of causation comes from, given that causation is unobservable, answering that it comes from our experience of the regular succession of certain kinds of events. The search for 'regularities' became a prominent feature of 'Humean' work on causation and Hempel 1942 spelled out its implications for causal explanation: he argued that we explain events by identifying them as instances of law like regularities (this is the so-called 'covering law' model of explanation) and that this is no less true in history and the social sciences than in the natural sciences. Mackie 1965 later articulated a more sophisticated Humean approach seeking to make sense of complex regularities of the kind often encountered in the social sciences. Collingwood 1937-8 asked a similar question to Hume but gave a very different answer: our core idea of causation is that of affording to another actor a motive to do something. The idea that causation is concerned with reasons for action is developed by Davidson 1963, who argued, against the prevailing wisdom, that reasons can be causes. This brings into question the categorical distinction between causal explanation and interpretive understanding drawn by scholars such as Hollis and Smith 1991. Lewis 1973, Bhaskar 2008[1975] and Cartwright 1989 are all reactions against the Humean tradition and its focus on regularities, Lewis defending in its place a counterfactual understanding of causation and Bhaskar and Cartwright both endorsing a form of causal realism in which the focus of causal inquiry is on identifying underlying causal powers, mechanisms, and capacities. Woodward 2003 develops an account of both causation and causal explanation as being concerned with the putative effects of interventions. Pearl 2009 is an influential exposition of the increasingly popular use of structural equation modelling for causal inference.

Bhaskar, Roy. A Realist Theory of Science. London: Verso, 2008[1975]. 
A key text in the development of Critical Realism, which has since become influential in IR as a challenge and alternative to mainstream approaches to causal inference. Bhaskar's key argument is that Humean accounts of natural science as involving the search for empirical regularities cannot be sustained; rather, natural science seeks to identify the causal powers and mechanisms that generate observed phenomena.

Cartwright, Nancy. Nature's Capacities and their Measurement. Oxford: Clarendon Press, 1989.

One of the most influential advocates of causal realism, Cartwright argues (against Hume) that things have causal capacities which are the subject of causal laws and which it is the task of science to discover.

Collingwood, RG. 'On the So-Called Idea of Causation'. Proceedings of the Aristotelian Society, New Series 38 (1937-8): 85-112.

Surveys different 'senses' in which the word cause (and cognate terms) have been used historically. Argues that, as the term was originally used, causing involved affording a motive to a human agent to act in a particular way and that the application of this causal discourse to natural phenomena should therefore be treated as 'metaphorical'.

Davidson, Donald. 'Actions, Reasons, and Causes'. The Journal of Philosophy 60, no. 23 (1963): 685700.

A seminal argument in favour of reasons being a species of cause. Implies that explaining an action by giving the actor's reasons for so acting constitutes a causal explanation.

Hempel, Carl G. 'The function of general laws in history'. The Journal of Philosophy 39, no. 2 (1942): 3548.

A seminal articulation of the so-called 'covering-law' model of explanation. Argues that it applies as much to explanation in History (and, by implication, the social sciences more broadly) as it does to explanation in the natural sciences.

Hume, David. Enquiries Concerning Human Understanding and Concerning the Principles of Morals. Reprinted from the 1777 edition with Introduction and Analytical Index by L. A. Selby-Bigge, $3^{\text {rd }}$ ed. (1975[1777]), 60-79. Oxford: Clarendon Press, 1975.

An accessible statement of Hume's influential take on causation. Makes clear, contrary to later mischaracterizations, that Hume did not identify causation as a species of regularity; his puzzle is not what causation is, but rather where we get our idea of causation from, given that it is unobservable.

Lewis, David. 'Causation'. The Journal of Philosophy 70, no. 17 (1973): 556-567. 
A crucial early statement of what was to become the counterfactual view of causation according to which the causes of some event, $E$, are just those preceding events without which $E$ would not have occurred. This kind of view underpins most accounts of causal inference in IR, especially those which advocate use of statistical methods.

Mackie, JL. 'Causes and Conditions'. American Philosophical Quarterly 2, no. 4 (1965): 245-64. Defends the view that, rather than stating necessary and sufficient conditions for the occurrence of some event or kind of event, many causal statements identify INUS conditions: Insufficient but Necessary parts of conditions which are themselves Unnecessary but Sufficient for the observed outcome. This framework is widely invoked as a tool for thinking about causal complexity in IR.

Pearl, Judea. Causality: Models, Reasoning, and Inference, $2^{\text {nd }}$ ed. Cambridge: Cambridge University Press, 2009.

Lays out a mathematical approach to causal inference based around the use of causal models in the form of directed acyclic graphs.

Woodward, James. Making Things Happen: A Theory of Causal Explanation. Oxford, Oxford University Press, 2003.

Develops the intuition that causal claims tell us something about the actual or counterfactual effects of interventions in the world to develop a manipulationist account of both causation and causal explanation.

\section{Edited Collections}

In addition to these seminal texts there are several useful edited collections in which some of the key arguments and responses to them can be found. Sosa 1975 and Sosa and Tooley 1993 collect a number of important statements about the nature of causation and how causes can be identified, including reprints of Mackie 1965 and Lewis 1973, as well as discussions of probabilistic approaches to causation. (The two volumes overlap somewhat, but each contains important contributions not found in the other.) Ruben 1993 collects key statements about causal explanation and how it is linked to causation. It includes a range of important arguments against the account of causal explanation defended in Hempel 1942. Of particular note, in their own right and because they have been drawn upon by those working on causal explanation in IR, are: Lewis's influential account of causal explanation as providing targeted information from extensive causal histories; Lipton's argument that causal explanation is contrastive, explaining why $P$ rather than $Q$, and Van Fraassen's contention that scientific explanations are always framed by pragmatic concerns. Collins 2004 collates developments in the counterfactual understanding of causation since Lewis's seminal statement (Lewis 1973). Beebee, Hitchcock and Menzies 2009 is a wide-ranging collection of contemporary statements by major philosophical figures which includes useful 
discussions of major approaches to causation that are drawn on or otherwise referenced in IR, including regularity, counterfactual, and probabilistic approaches and those which focus on causal mechanisms and/or causal powers and capacities.

Beebee, Helen, Christopher Hitchcock, and Peter Menzies, eds. The Oxford handbook of causation. Oxford: Oxford University Press, 2009.

A broad survey of current thinking about causation by philosophers. Many chapters are not directly relevant to IR, but the book provides a clear sense of the range of philosophical issues which lie behind more applied debates in IR and the extent of the ongoing disagreement about them.

Collins, John, Ned Hall, and LA Paul, eds. Causation and Counterfactuals. Cambridge, Mass.: MIT Press, 2004.

Contains a number of important essays, mostly written for this volume, on counterfactual approaches to causation, focusing on developments since Lewis 1973.

Ruben, David-Hillel, ed. Explanation. Oxford: Oxford University Press, 1993.

Incorporates a range of key statements by philosophers of science on the nature of scientific explanation and how it connects to causation, including arguments that have proved influential in discussions of causal explanation in IR.

Sosa, Ernest, ed. Causation and Conditionals. Oxford: Oxford University Press, 1975.

Brings together important essays on the nature of causation and on conditional statements and the relationship between the two.

Sosa, Ernest and Michel Tooley, eds. Causation. Oxford: Oxford University Press, 1993.

Incorporates a number of the essays in Sosa 1975, but adds important statements on probabilistic and counterfactual approaches to causation.

\section{Causation in the Philosophy of Social Science}

What distinguishes debates about causation in the philosophy of social science from the discussions surveyed above is their focus on the significant challenges posed for causal inquiry by the distinctive characteristics of the social world. One question raised is whether causal inquiry is even possible in the social sciences. Among the positive answers that have been given, three are especially relevant to IR. Hollis and Smith 1991 argue that because meanings are central to social life there are always two stories to tell, one causal and explanatory and the other interpretive, and that these can never be fully reconciled or integrated. By contrast, Elster 2007 argues that interpretation is explanation and that social life can be explained if we focus on causal mechanisms and on the beliefs and desires which make individual actions rationally intelligible. Bhaskar 2015[1979] contends that causal inquiry within a world of meanings 
requires us to go beyond a focus on individual agents and identify the social and material structures which shape and are also shaped by human agency. He insists, however, that doing this necessarily gives rise to a criticalsocial science. Another question is whether there is a single, unified understanding of or approach to causation in the social sciences. Brady 2009 identifies four principal approaches and argues that causal inquiry should seek to satisfy the requirements of all four. Within political science, both Gerring 2005 and Mahoney 2008 claim that it is possible to identify unifying approaches to causation, though they propose different candidates. Cartwright 2007 argues that different approaches to causation describe different kinds of causal relations and hence only fit certain kinds of cases. One concern this raises is that dominant methods of causal inquiry in the social sciences may rest on assumptions about the nature of the social world and the kinds of causal relations it contains which make them inappropriate for investigating some (perhaps many) kinds of social phenomena (see Abbott 1988). A third question concerns the nature and significance of causal mechanisms. It is widely believed that because universal laws are rare in the social sciences, causal inquiry should focus on discovering the mechanisms by which observed outcomes are produced (see, for example, Elster 2007; Bhaskar 2015). However, there is significant disagreement over the nature of causal mechanisms, the contribution they make to explanation, and their methodological implications (see Hedström and Ylikoski 2010; Kincaid 2012: chs.2$4)$.

Abbott, Andrew. 'Transcending General Linear Reality'. Sociological Theory6, no. 2 (1988): 169-186. Argues that the assumptions required by the most dominant methods of causal inquiry in the social sciences (viz. quantitative and statistical methods) are deeply problematic if taken as a model of social life and the kinds of causal relations it contains.

Bhaskar, Roy. The Possibility of Naturalism: A Philosophical Critique of the Contemporary Human Sciences, $4^{\text {th }}$ ed. London: Routledge, 2015[1979].

Argues that properly scientific inquiry into the causal relations which govern social life is possible only if we move beyond both a positivist approach to causality and an interpretive rejection of its applicability to the social world and instead draw on the realist approach outlined in Bhaskar 2008[1975]. Contends that such inquiry must identify the generative mechanisms which give rise to social laws and that these include large-scale social structures.

Brady, Henry E. 'Causation and Explanation in Social Science'. In The Oxford Handbook of Political Methodology. Edited by Janet M. Box-Steffensmeier, Henry E. Brady and David Collier, 217-270. Oxford: Oxford University Press, 2009.

Provides an introductory overview of some of the main approaches to causation employed in the social sciences, identifying some of the philosophical issues they raise and indicating why these make causal inference so difficult. 
Cartwright, Nancy. Hunting Causes and Using Them: Approaches in Philosophy and Economics.

Cambridge: Cambridge University Press, 2007.

Makes the case that in the social sciences rival understandings of causation are employed and that they are appropriate for generating knowledge of different kinds of causal relations. Illustrates this claim through a detailed examination of how different approaches to causation are drawn upon in Economics.

Elster, Jon. Explaining Social Behaviour: More Nuts and Bolts for the Social Sciences. Cambridge: Cambridge University Press, 2007.

A significantly revised and extended version of Elster's influential Nuts and Bolts for the Social Sciences (Cambridge University Press, 1989), it makes the case for a focus on causal mechanisms in the social sciences, but has been widely criticized for its methodological individualism and reliance on rational choice theory. Also offers an introduction to a range of broader issues in the philosophy of social science.

Gerring, John. 'Causation: A Unified Framework for the Social Sciences'. Journal of Theoretical Politics 17, no. 2 (2005): 163-98.

Argues against the idea that there are plural conceptions of causation and for a unitary understanding which can underpin all the others, viz. the idea that a cause raises the probability of an event. Uses this as a basis from which to develop criteria for good causal arguments.

Hedström, Peter, and Petri Ylikoski. 'Causal Mechanisms in the Social Sciences'. Annual Review of Sociology 36 (2010): 49-67.

Reviews different understandings of causal mechanisms in the social sciences and lays out a series of ways in which mechanisms are drawn upon in causal explanations.

Hollis, Martin, and Steve Smith. Explaining and Understanding International Relations. Oxford: Clarendon Press, 1991.

Provides a useful introduction to debates in the philosophy of social science about how social life can be explained, including illustrations drawn from IR. However, its distinction between (causal) explanation and (interpretive) understanding has been widely criticised as resting on an overly restrictive account of what causal inquiry consists in.

Kincaid, Harold, ed. The Oxford Handbook of Philosophy of Social Science. Oxford: Oxford University Press, 2012. 
Provides an overview of contemporary philosophy of social science. Includes a series of useful chapters surveying recent ideas about causal mechanisms and causal complexity.

Mahoney, James. 'Toward a Unified Theory of Causality'. Comparative Political Studies 41, no. 4/5 (2008): 412-36.

Surveys competing conceptualizations of causation in comparative research, noting an important difference between the approaches used in qualitative (case study) and quantitative (statistical) research. Argues that the approach used in case study research, viz. identifying INUS conditions (see Mackie 1980), underpins all the others and should hence be viewed as a unifying approach.

\section{Causation in International Relations - Key Ideas}

Discussions of causation in IR tend to focus on one of four areas, each of which is examined in detail below: (i) causal inference, (ii) scientific and critical realism, (iii) causal explanation, and (iv) history and causal inquiry. Of these, by far the most extensive literature is that which focuses on causal inference, and especially on the relative merits of quantitative and qualitative methods for causal inference. However, while this literature is extensive and has a good claim to represent mainstream thinking about causation within IR, its philosophical underpinnings are contentious. This is reflected in the emergence of the other three literatures, each of which is motivated to a significant degree by dissatisfaction with the narrowness of mainstream discussions of causal inference.

\section{Causal Inference}

The aim of the literature on causal inference is to identify the methods which can most reliably be used to generate causal knowledge from the study of one or more empirical cases. It does not distinguish strongly between IR and Political Science, but rather draws on examples from both and advances arguments intended to apply to both. The single most influential text is King, Keohane, and Verba 1994, which is widely used on research methods courses in IR. Its central argument is that qualitative research can be strengthened by applying many of the ideas and tools employed in quantitative research. In particular, it advocates increasing the number of observations used for causal inference in order to avoid potentially damaging forms of bias. This message has since been further developed in an extensive and sophisticated literature exploring how statistical methods can be used to overcome the limitations of more traditional qualitative methods (see, for example, Sekhon 2004). One important kind of pushback against this message has come from qualitative researchers who contend that King, Keohane and Verba do not do justice to the distinctive strengths of case study approaches (on which see Van Evera 1997; George and Bennett 2005). Brady and Collier 2010 collates many of the most important contributions to this debate and also advances an influential argument of its own about the value of process-tracing methods for identifying causal mechanisms (see also George and Bennett 2005; Beach and Pedersen 2013). This pushback has led to the emergence of a sustained debate between adherents of quantitative and 
qualitative approaches to causal inference (see Mahoney and Goertz 2006). However, an important characteristic of this debate is the acceptance by the major contributors (see, for example, King, Keohane, and Verba 1994; Mahoney and Goertz 2006; Brady and Collier 2010) that, whatever their relative merits, qualitative and quantitative approaches participate in a shared logic of causal inference. This has led to a second important line of pushback from critics who point out the limitations of this shared understanding. Both Johnson 2006 and Jackson 2011 argue that while King, Keohane and Verba seek to avoid being drawn into philosophical discussions, the logic of inference they describe is in fact distinctively (neo)positivist, and that this imposes unwarranted restrictions on the scope and content of causal inquiry. This critique explicitly or implicitly informs each of the other three literatures on causation in IR surveyed below.

Beach, Derek and Rasmus Brun Pedersen. Process-Tracing Methods: Foundations and Guidelines. Ann Arbor: University of Michigan Press, 2013.

An influential book-length study of process-tracing in social science research. Combines reflection on the nature and significance of causal mechanisms with practical guidance for implementing processtracing methods.

Brady, Henry E., and David Collier. Rethinking Social Inquiry: Diverse Tools, Shared Standards, $2^{\text {nd }}$ ed. Lanham: Rowman \& Littlefield, 2010.

A revised and significantly expanded edition which both collates some of the most important responses to King, Keohane, and Verba 1994 and develops an influential argument of its own about the power of process tracing as a tool of qualitative inference aimed at identifying causal mechanisms.

George, Alexander L. and Andrew Bennett. Case Studies and Theory Development in the Social Sciences. Cambridge, Mass.: MIT Press, 2005.

An influential guide to the application of a range of qualitative, case study methods to support causal inference in the social sciences, drawing heavily on examples from IR.

Jackson, Patrick Thaddeus. The Conduct of Inquiry in International Relations: Philosophy of Science and its Implications for the Study of World Politics. Abingdon: Routledge, 2011.

Argues that advocates of quantitative and qualitative methods for causal inference share a neopositivist stance on how scientific knowledge of the social world is possible. As neopositivism is one of only four competing 'philosophical ontologies' that are widely drawn upon to support scientific inquiry in IR, this indicates the narrowness of the debate and the degree to which it rests on powerful and questionable, if usually implicit, philosophical assumptions. 
Johnson, James. 'Consequences of Positivism: A Pragmatist Assessment'. Comparative Political Studies 39, no. 2 (2006): 224-52.

Argues that although King, Keohane, and Verba 1994 claims to avoid philosophical entanglements, it in fact embodies a distinctive form of positivism. Furthermore, this positivism provides scant resources for explaining the robust statistical patterns which it seeks to discover.

King, Gary, Robert O. Keohane, and Sidney Verba. Designing Social Inquiry: Scientific Inference in Qualitative Research. Princeton: Princeton University Press, 1994.

Argues that there is a single logic of inference in the social sciences which applies to both quantitative and qualitative methods but which is often more clearly articulated in quantitative approaches. Drawing on the statistical template, advances a series of recommendations for improving qualitative forms of causal inquiry, focused around increasing the number of observations and avoiding bias.

Mahoney, James and Gary Goertz. 'A Tale of Two Cultures: Contrasting Quantitative and Qualitative Research'. Political Analysis 14, no. 3 (2006): 227-49.

A systematic comparison of quantitative and qualitative research traditions which emphasizes their differences but also accepts that they share an overarching understanding of causal inference.

Sekhon, Jasjeet S. 'Quality Meets Quantity: Case Studies, Conditional Probability, and Counterfactuals. Perspectives on Politics 2, no. 2 (2004): 281-93.

An exemplary discussion of the weaknesses of traditional qualitative approaches to causal inference based on the methods of difference and agreement and of how statistical techniques can be used to strengthen them.

Van Evera, Stephen. Guide to Methods for Students of Political Science. Ithaca: Cornell University Press, 1997.

A widely used and influential guide to the application of case study methods in IR and political science, aimed principally at PhD students.

\section{Scientific and Critical Realism}

The strongest and most sustained critique of the mainstream approach to causal inference in IR has come from scientific and critical realists who join Johnson 2006 and Jackson 2011 in criticizing its (neo)positivist underpinnings. In particular, they criticize its focus on identifying observable regularities (see Kurki 2008), the limited ways in which it conceptualizes deep, but unobservable social structures (see Wendt 1999), and its neglect of causal complexity (see Patomäki 2002). Drawing strongly on Bhaskar 2008 and Bhaskar 2015, scientific and critical realists seek to reconstitute causal inquiry in IR along philosophically realist lines. At its most basic, this means seeking to 'provide explanations at a 
deeper level of understanding' (Wight 2006: 18) and it requires three major shifts of emphasis. The first is from epistemology to ontology: from a focus on asking when inferences can justifiably be derived from particular data sources to a focus on conceptualizing the various entities and relations which constitute world politics. The second shift is from regularities to mechanisms: from seeking to identify empirical patterns to seeking to identify the causal mechanisms and powers which generate them. The third shift is from (mere) explanation to critique: from identifying how things work to identifying the ways in which they could work differently. In calling for this reorientation, scientific and critical realists apply to IR a set of ideas that are relevant across the social sciences. The first major work in IR to explicitly root itself in Scientific Realism [SR] was Wendt 1999, while Patomaki and Wight 2000 constituted an early and influential manifesto statement on behalf of Critical Realism [CR] in IR. Key contributions in the development of CR within IR include Patomäki 2002, Wight 2006, and Kurki 2008, while Joseph et al 2007 provides a useful introduction to the issues. Joseph and Wight 2010 illustrates the range of substantive issues that a commitment to SR/CR might help to illuminate. Critics have tended to be sympathetic to the SR/CR critique of the mainstream approach to causal inference in IR, but to take issue with the contention that SR/CR constitutes the only viable alternative to it. Both Chernoff 2002 and Humphreys 2019 identify anti-realist alternatives to SR/CR which also offer a critical perspective on the assumptions of the mainstream approach, while Jackson 2011 situates CR as one of four major philosophically informed approaches that are drawn upon in IR (neopositivism being another).

Chernoff, Fred. 'Scientific Realism as a Meta-Theory of International Politics'. International Studies Quarterly 46, no. 2 (2002): 189-207.

Contends that arguments for SR in IR (especially that presented by Wendt 1999) tend to misrepresent non-SR positions, making it seem (wrongly) as if there are no viable alternative philosophical positions that could support wide-ranging forms of empirical and causal inquiry. Defends one such alternative in particular, viz. Duhemian conventionalism.

Humphreys, Adam RC. 'Realism, Empiricism and Causal Inquiry in International Relations: What is at Stake?' European Journal of International Relations 25, no. 2 (2019): 562-87.

Contends that arguments for SR/CR and against the empiricism which is said to underpin mainstream methods of causal inference in IR are flawed insofar as they take aim at forms of empiricism which are no longer defended in contemporary philosophy of science. Argues that Van Fraassen's constructive empiricism (see Van Fraassen 1980) in fact offers considerable support to SR/CR critiques of mainstream methods in IR.

Jackson, Patrick Thaddeus. The Conduct of Inquiry in International Relations: Philosophy of Science and its Implications for the Study of World Politics. Abingdon: Routledge, 2011. 
Discusses $\mathrm{CR}$ as one of four philosophical ontologies drawn upon to support empirical and causal inquiry in IR. Broadly endorses the CR critique of neopositivism, but adopts a sceptical stance on some of its substantive ontological and methodological claims.

Joseph, Jonathan, Milja Kurki, Colin Wight, Fred Chernoff, and Chris Brown. 'Forum: Scientific and Critical Realism in International Relations'. Millennium: Journal of International Studies 35, no. 2 (2007): 343-416.

Provides a useful introduction to the debate around CR in IR, including statements by three key proponents (Joseph, Kurki, and Wight) and responses from two critics (Chernoff and Brown).

Joseph, Jonathan, and Colin Wight, eds. Scientific Realism and International Relations. Basingstoke: Palgrave Macmillan, 2010.

A collection of essays which seeks to show how adoption of SR/CR can and does influence research practices and shape understandings of substantive issues in IR. Provides a useful insight into the substantive implications of meta-theoretical positions on causation and related issues.

Kurki, Milja. Causation in International Relations: Reclaiming Causal Analysis. Cambridge Studies in International Relations vol. 108. Cambridge: Cambridge University Press, 2008.

Draws on $\mathrm{CR}$ ideas to criticize the focus on regularities in mainstream approaches to causal inference in IR and to support a call for a 'deeper and broader' understanding of causation which expands the range of problems that causal analysis in IR can address and the range of methods it can employ.

Patomäki, Heikki. After International Relations: Critical Realism and the (Re)Construction of World Politics. London: Routledge, 2002.

A collection of essays which seeks to show how $\mathrm{CR}$, with its emphasis on both explanatory depth and emancipatory critique, can be employed to redirect the discipline of IR towards the identification of transformative possibilities within world politics.

Patomaki, Heikki, and Colin Wight. 'After Postpositivism? The Promises of Critical Realism'. International Studies Quarterly 44, no. 2 (2000): 213-37.

An early manifesto statement for CR in IR. Argues that a crucial but largely unrecognized feature of the debate between positivists and postpositivists in IR is that both approaches are philosophically anti-realist. Presents $\mathrm{CR}$ as an approach which can overcome the resulting sterility of the positivistpostpositivist debate, combining the causal inquiry prized by the positivists with the critical stance prized by the postpositivists. 
Wendt, Alexander. Social Theory of International Politics. Cambridge Studies in International Relations vol. 67. Cambridge: Cambridge University Press, 1999.

A hugely influential statement of constructivist theory, it is also one of the earliest articulations and defences of SR in IR. Stresses the reality of unobservable social structures and the centrality of mechanisms for causal explanation.

Wight, Colin. Agents, Structures and International Relations: Politics as Ontology. Cambridge Studies in International Relations vol. 101. Cambridge: Cambridge University Press, 2006.

Draws on CR ideas, especially concerning the centrality of ontological questions in (social) scientific inquiry, to interrogate treatments of the agent-structure problem in IR and reveal the consequences of different ways of addressing this problem. Argues that theoretical disagreements within IR are best understood as reflecting competing ontological visions.

\section{Causal Explanation}

One of the most important lines of criticism advanced against King, Keohane, and Verba is that they provide an inadequate account of causal explanation and how it connects to causal inference (see Johnson 2006; Brady and Collier 2010). This exemplifies a broader pattern in which work on causation in IR has focused on how reliable causal knowledge can be derived, rather than on how it is applied in causal explanations. In recent years, however, philosophically-minded scholars in IR have begun to analyse causal explanation as a distinctive kind of activity, drawing on the substantial philosophical literature on explanation and how it relates to causation (see Lipton 2009; see also Ruben 1993). An important ground-clearing exercise has been to establish the inadequacy of the covering-law model of explanation (see Wendt 1999; Suganami 2008; Jackson 2017; see also Hempel 1942). This done, theorists of causal explanation in IR have emphasized the idea that an explanation constitutes an answer to a question, resolving some puzzle on the part of the questioner. Thus Suganami 2008 has explored the ingredients of causal explanations and how they may differ depending on what we want to know,

Grynaviski 2013 has emphasized how the kind of question that is asked determines what is explanatorily relevant, Jackson 2017 stresses the distinction between causal explanations and the kinds of causal claims for which support is derived via causal inferences, arguing that causal explanation is a distinctively pragmatic activity, and Humphreys 2017 argues that because causal explanations answer specific questions, evaluation of competing causal explanations must have a pragmatic dimension. There is also increasing recognition of the broader significance of how we think about explanation. For example, Chernoff 2014 argues that progress within several important debates in security studies is limited by a lack of agreement about criteria for explanatory superiority, while Kurki and Suganami 2011 argue that many critical theorists reject causal analysis based in part on rather vague understandings of what is involved in causal explanation. 
Chernoff, Fred. Explanation and Progress in Security Studies: Bridging Theoretical Divides in

International Relations. Stanford: Stanford University Press, 2014.

Draws on the philosophy of science to identify a range of ways in which 'explanation' can be understood. He then considers how it is in fact understood in several prominent debates within security studies and argues that the lack of progress in these debates is, in part, due to competing claims about what counts as 'explanatory superiority'.

Grynaviski, Eric. 'Contrasts, Counterfactuals, and Causes'. European Journal of International Relations 19, no. 4 (2013): 823-46.

Argues that many practical research questions in IR take the form 'Why $p$ rather than $q$ ?' and that this indicates the merits (and unifying potential) of a contrastive, counterfactual understanding of causation and causal explanation. Illustrates this in relation to debates about the causes of the Cuban Missile Crisis.

Humphreys, Adam RC. 'Causation, Complexity, and the Concert: The Pragmatics of Causal Explanation in International Relations'. Journal of International Relations and Development 20, no. 4 (2017): 717-36. Argues that causal explanations inherently involve pragmatic choices about which parts of causal histories are relevant to the question being asked and that adjudication between competing causal explanations therefore involves pragmatic as well as epistemic judgements. Illustrates this claim in relation to the ongoing debate about what explains the relative peacefulness of the nineteenthcentury Concert system.

Jackson, Patrick Thaddeus. 'Causal Claims and Causal Explanation in International Studies'. Journal of International Relations and Development 20, no. 4 (2017): 689-716.

Distinguishes between the law-like generalizations for which mainstream approaches to causal inference in IR seek to develop evidence and causal explanations, arguing that explanation is an intrinsically pragmatic activity and that appeal to law-like generalizations is only one of many possible explanatory strategies.

Kurki, Milja and Hidemi Suganami. 'Towards the Politics of Causal Explanation: A Reply to the Critics of Causal Inquiries'. International Theory 4, no. 3 (2012): 400-429.

Defends causal inquiry in IR against critics who contend that it is politically conservative and hence that critical approaches to world politics must be non-causal. Argues that such contentions are informed by vague and/or underdeveloped conceptions of causation and causal explanation and a narrow understanding of the kinds of questions causal inquiry can help to answer. 
Lipton, Peter. 'Causation and Explanation'. In The Oxford Handbook of Causation. Edited by Helen Beebee, Christopher Hitchcock and Peter Menzies, 619-31. Oxford: Oxford University Press, 2009.

Provides a brief introduction to the philosophical considerations which arise in thinking about the relationship between causation and explanation.

Suganami, Hidemi. 'Narrative Explanation and International Relations: Back to Basics'. Millennium: Journal of International Studies 37, no. 2 (2008): 327-56.

Argues that the 'covering-law model of explanation' is irrevocably flawed and that causal explanations are processual - they tell us how a segment of the world moved from one state to another. Narratives about how this occurred can be conceptualized as containing three principal characteristic ingredients: chance coincidences, mechanistic processes, and human acts.

\section{History and Causal Inquiry}

One of the key questions raised in the debate about the relative merits of quantitative and qualitative methods of causal inference, and in the broader critiques of that debate, is whether historical inquiry can generate causal knowledge. This connects to a long-standing debate about the relationship between theoretical and historical approaches, methods, and sensibilities within IR (see Schroeder 1997; Smith 1999; Elman and Elman 2001; Suganami 2008; Lawson 2012). Büthe 2002 exemplifies one widespread view, most commonly defended by proponents of quantitative methods of causal inference, that the function of history in causal inquiry is not to generate causal knowledge, but rather to provide the evidence (whether in the form of event data or narratives) against which theories can be tested. However, this view is problematized by the diversity of historiographical interpretation which characterizes historical inquiry (see Smith 1999). Moreover, as Schroeder 1997 points out, many historians explicitly conceive of themselves as identifying causes. What historians reject is not causal inquiry as such, but rather restrictive accounts, derived from science and social science, of how historical inquiry into causes must proceed (see Ringer 1989; cf Hempel 1942). An alternative view, therefore, is that history is (or can be) a form of causal inquiry in its own right, but that historians typically have different priorities and emphases from social scientists. Thus, for example, Schroeder 1997 argues that historians, more than political scientists, focus on explaining change and seek to synthesize multiple sources of evidence, while Suganami 2008 argues that historians often place a greater emphasis on chance and human action than social scientists, who place a greater emphasis on causal mechanisms (see also Elman and Elman 2001). This latter view suggests that the difference between the causal explanations generated by social scientists and historians is one of degree, rather than of kind. This is reflected in the increased focus within IR and political science on the kinds of causes that are emphasized in historical inquiry (see Mahoney, Kimball and Koivu 2009), the relationship between process tracing and history (see Mahoney 2015), and the ways in which historians draw on counterfactual claims to support causal inferences (see Levy 2015). 
Büthe, Tim. 'Taking Temporality Seriously: Modelling History and the Use of Narratives as Evidence'.

American Political Science 96, no. 3 (2002): 481-93.

Makes the case for developing theoretical models of historical processes and for using the narratives produced by historians as data against which to test these models.

Elman, Colin, and Miriam Fendius Elman, eds. Bridges and Boundaries: Historians, Political Scientists, and the Study of International Relations. Cambridge, Mass.: MIT Press, 2001.

Brings together historians and political scientists to reflect on the relationship between historical and theoretical approaches to international relations. Includes illustrative examples of how historians and political scientists have approached the same issues in different ways.

Lawson, George. 'The Eternal Divide? History and International Relations'. European Journal of International Relations 18, no. 2 (2012): 203-26.

Explores the relationship between History and IR, rejecting the idea of an unbridgeable disciplinary divide. Argues that once we look beyond the problematic views of history that still thrive in IR we can recognize social science and history as co-implicating endeavours drawing on shared tools.

Levy, Jack S. 'Counterfactuals, Causal Inference, and Historical Analysis'. Security Studies 24, no. 3 (2015): 378-402.

Considers how historians draw on counterfactual analysis to derive causal inferences and suggests criteria for the use of such analyses.

Mahoney, James. 'Process Tracing and Historical Explanation'. Security Studies 24, no. 2 (2015): 200218.

Examines the commonalities between process tracing and historical explanation and makes the case for more self-conscious and transparent use of process tracing methods by historians.

Mahoney, James, Erin Kimball, and Kendra L. Koivu. 'The Logic of Historical Explanation in the Social Sciences'. Comparative Political Studies 42, no. 1 (2009): 114-46.

Reviews the types of causes that are invoked in historical explanations in the social sciences and suggests a method for evaluating the relative importance of particular causes.

Ringer, Fritz K. 'Causal Analysis in Historical Reasoning'. History and Theory 28, no. 2 (1989): 154-72. Argues that historians have always talked about causes, but that the predominant accounts of historians' causal reasoning, such as that offered in Hempel 1942, are inadequate. Defends a view of history as developing causal explanations that include actors' reasons. 
Schroeder, Paul W. 'History and International Relations Theory: Not Use or Abuse, but Fit or Misfit'. International Security 22, no. 1 (1997): 64-74.

Comments on the relationship between historical and theoretical approaches to the study of international relations, arguing that IR theorists often misunderstand what it is that historians take themselves to be doing and hence misrepresent the relationship between IR and History.

Smith, Thomas W. History and International Relations. London: Routledge, 1999.

Analyses the ways in which history has been conceptualized and understood in IR, arguing that much of IR theory is troublingly ahistorical insofar as it treats history as an unproblematic background narrative against which theories can be tested. Denies that there is or should be any essential divide between IR and History.

Suganami, Hidemi. 'Narrative Explanation and International Relations: Back to Basics'. Millennium: Journal of International Studies 37, no. 2 (2008): 327-56.

Rejects attempts to distinguish IR from International History on the basis of the kinds of explanations they seek, arguing that both generate narrative explanations, even if these narratives often emphasize different kinds of causal factors.

\section{Causation in International Relations - Selected Examples}

Because of the abstract nature of philosophical debates about causation and the range of concerns canvassed in debates about causation in IR, one of the best ways to get a handle on why such debates matter for substantive research is to examine work which explicitly spells out how particular understandings of or approaches to causation shape understandings of substantive issues. A common theme in such work is that replacing dominant ways of thinking with more philosophically informed alternatives will facilitate progress in addressing substantive issues (see, for example, Dessler 1991; Suganami 1996; Yee 1996; Guzzini 2011; Chernoff 2014). One broad contention made in such work is that it is a mistake to treat causation as a kind of regularity or to treat correlations as the principal form of evidence for the presence of causal relations. Yee 1996 shows how this makes it difficult to get to grips with the causal effects of ideas and beliefs and Guzzini 2011 develops this theme, arguing that in order to make sense of the explanatory power of securitization theory it is necessary to conceive of causal mechanisms as more than just intervening variables. Dessler 1991 shows how research on war has been hamstrung by a focus on correlations rather than mechanisms, while Suganami 1996 argues that thinking about causation in terms of regularities limits the range of questions that it is possible to ask and answer about the causes of war. Patomäki 2008 seeks to show how a focus on identifying deeper mechanisms can facilitate both causal explanation and scenario forecasting. A second broad contention is that mainstream approaches in IR do not do justice to different ways of thinking about causal explanation or to 
the range of methods that can be used in causal inquiry, especially historical methods. For example, Suganami 1996 shows that in order to conduct effective research into the causes of war it is necessary to think carefully about what it is we are trying to explain, while Chernoff 2014 demonstrates the impact on several prominent debates within security studies of a lack of consensus on how to think about explanation. Goertz and Levy 2007 collate substantive examples of historians and political scientists employing counterfactual arguments to support causal claims, while Kocher and Monteiro 2016 illustrate how even natural experiments rely on historical evidence.

\section{Chernoff, Fred. Explanation and Progress in Security Studies: Bridging Theoretical Divides in}

International Relations. Stanford: Stanford University Press, 2014.

Explores how 'explanation' is understood in debates about the causes of nuclear proliferation, alliance building, and the democratic peace, and argues that progress within these debates is limited by the failure of contributors to identify clearly what criteria of explanatory superiority they use in evaluating competing explanations.

Dessler, David. 'Beyond Correlations: Toward a Causal Theory of War'. International Studies Quarterly 35, no. 3 (1991): 337-55.

Argues that the lack of progress in the study of war is a function of the correlational approach that predominates and makes the case for an approach rooted in a realist understanding of science and focused on the identification of causal mechanisms.

Goertz, Gary and Jack S. Levy, eds. Explaining War and Peace: Case Studies and Necessary Condition Counterfactuals. London: Routledge, 2007.

Collates examples of historians and political scientists drawing on counterfactual reasoning to support inferences about the causes of WW1 and of the end of the Cold War. An introductory essay elaborates the form of reasoning involved and its potential explanatory power.

Guzzini, Stefano. 'Securitization as a Causal Mechanism'. Security Dialogue 42, nos.4-5 (2011): 329-41. Argues that securitization theory should be understood as describing a causal mechanism, but that in order to make sense of how a causal mechanism can be embedded within foreign policy discourse it is necessary to conceive of mechanisms in non-positivist terms.

Kocher, Matthew A and Nuno P Monteiro. 'Lines of Demarcation: Causation, Design-Based Inference, and Historical Research'. Perspectives on Politics 14, no. 4 (2016): 952-75.

Argues that our confidence in causal inferences derived through natural experiments (which are increasingly used within IR and political science) depends on historical evidence concerning the causal process through which the data was generated. They illustrate this through a close 
examination of a recent, historically-derived natural experiment concerning the effect of devolving power to local elites on violent resistance to foreign occupation.

Patomäki, Heikki. The Political Economy of Global Security: War, Future Crises and Changes in Global Governance. London: Routledge, 2008.

Drawing on Critical Realism, and especially the methodology for modelling causal complexes outlined in Patomäki 2002, seeks to show how systematic causal analysis of existing structures and processes can be used to support anticipations of the future. Argues that some of the central mechanisms, tendencies, and contradictions in the contemporary international system are in important respects similar to those which led to economic and political crises in the pre-WW1 era.

Suganami, Hidemi. On the Causes of War. Oxford, Oxford University Press, 1996.

Contends that literature in IR on the causes of war does not clearly distinguish several different kinds of questions we might ask about the causes of war and shows how answering questions about the causes of specific wars requires us to move beyond regularity theories of causation and causal explanation.

Yee, Albert S. 'The Causal Effects of Ideas on Policies'. International Organization 50, no. 1 (1996): 69108.

Argues that attempts to make the case that ideas and beliefs are causally efficacious in international relations are hampered by adherence to correlational approaches to causation and that the causal effects of ideas can be better grasped if we conceptualize causation in terms of causal powers and capacities and conceive of ideas as having such capacities. 